PCSK9, apolipoprotein E and lipoviral particles in chronic hepatitis $\mathrm{C}$ genotype 3: Evidence for genotype-specific regulation of lipoprotein metabolism

\title{
Bridge, SH
}

http://hdl.handle.net/10026.1/4255

10.1016/j.jhep.2014.11.016

Journal of Hepatology

Elsevier BV

All content in PEARL is protected by copyright law. Author manuscripts are made available in accordance with publisher policies. Please cite only the published version using the details provided on the item record or document. In the absence of an open licence (e.g. Creative Commons), permissions for further reuse of content should be sought from the publisher or author. 


\title{
PCSK9, apolipoprotein E and lipoviral particles in chronic hepatitis $C$ genotype 3: Evidence for genotype-specific regulation of lipoprotein metabolism
}

\author{
Simon H. Bridge ${ }^{1,2, *}$, David A. Sheridan ${ }^{1,3}$, Daniel J. Felmlee, ${ }^{1,4}$, Mary M.E. Crossey ${ }^{5}$, \\ Fiona I. Fenwick ${ }^{1}$, Clare V. Lanyon ${ }^{2}$, Geneviève Dubuc ${ }^{6,9}$, Nabil G. Seidah ${ }^{7,9}$, \\ Jean Davignon ${ }^{6,9}$, Howard C. Thomas ${ }^{5}$, Simon D. Taylor-Robinson ${ }^{5}$, \\ Geoffrey L. Toms ${ }^{1}$, R. Dermot G. Neely ${ }^{1,8}$, Margaret F. Bassendine ${ }^{1, *}$
}

\begin{abstract}
${ }^{1}$ Institute of Cellular Medicine, Newcastle University, Newcastle upon Tyne, United Kingdom; ${ }^{2}$ Faculty of Health and Life Sciences, Northumbria University, Newcastle upon Tyne, United Kingdom; ${ }^{3}$ Institute of Translational \& Stratified Medicine, Plymouth University Peninsula School of Medicine E Dentistry, United Kingdom; ${ }^{4}$ Inserm U1110, University of Strasbourg and Center for Liver and Digestive Diseases, Strasbourg University Hospitals, 3 Rue Koeberlé, F-67000 Strasbourg, France; ${ }^{5}$ Liver Unit, Department of Medicine, Imperial College London, St Mary's Hospital Campus, Praed Street, London, United Kingdom; ${ }^{6}$ Hyperlipidemia and Atherosclerosis Research Group, Clinical Research Institute of Montréal (IRCM), Montréal, Canada; ${ }^{7}$ Laboratory of Biochemical Neuroendocrinology, Clinical Research Institute of Montréal, Montréal, Canada;

${ }^{8}$ Department of Clinical Biochemistry, Newcastle upon Tyne Hospitals NHS Foundation Trust, Royal Victoria Infirmary, United Kingdom;

${ }^{9}$ University of Montréal, Montréal, Canada
\end{abstract}

Background \& Aims: Hepatitis C virus (HCV) associates with lipoproteins to form "lipoviral particles" (LVPs) that can facilitate viral entry into hepatocytes. Initial attachment occurs via heparan sulphate proteoglycans and low-density lipoprotein receptor (LDLR); CD81 then mediates a post-attachment event. Proprotein convertase subtilisin kexin type 9 (PCSK9) enhances the degradation of the LDLR and modulates liver CD81 levels. We measured

\footnotetext{
Keywords: HCV lipoviral particles; HDL-C; Apolipoprotein E; PCSK9; Low-density lipoprotein receptor; Apolipoprotein A1.

Received 17 March 2014; received in revised form 28 October 2014; accepted 12 November 2014; available online 21 November 2014

* Corresponding authors. Addresses: NB119, Northumberland Building, Faculty of Health and Life Sciences, Northumbria University, Newcastle upon Tyne NE1 8ST, United Kingdom. Tel.: +44 (0) 1912274808 (S.H. Bridge). Institute of Cellular Medicine (Hepatology), 2nd Floor, William Leech Building, The Medical School, Newcastle University, Newcastle upon Tyne NE2 4HH, United Kingdom. Tel.: +44 (0) 191213 7208; fax: +44 (0) 1912080723 (M.F. Bassendine).

E-mail addresses: simon.bridge@northumbria.ac.uk (S.H. Bridge), margaret. bassendine@newcastle.ac.uk (M.F. Bassendine).

Abbreviations: PCSK9, proprotein convertase subtilisin-like kexin type 9; HCV, hepatitis C virus; LVP, lipoviral particle; LDLR, low-density lipoprotein receptor; G, genotype; HCV RNA, hepatitis C virus ribonucleic acid; RT-PCR, reverse transcriptase polymerase chain reaction; IR, insulin resistance; HOMA-IR, homeostatic model of assessment of insulin resistance; ELISA, enzyme-linked immunoabsorbent assay; HCV-G3, hepatitis C virus genotype 3; HCV-G1, hepatitis C virus genotype 1; HDL-C, high-density lipoprotein cholesterol; $r$, coefficient of correlation; $p, p$ value; ApoE, apolipoprotein E; LVPr, lipoviral particle ratio; $R^{2}$, coefficient of determination; HIV, human immunodeficiency virus; VLDL, very low density lipoprotein; ApoB, apolipoprotein B; ApoC-I, apolipoprotein C-I; ApoA-I, apolipoprotein A-I; HSPG, heparan sulphate proteoglycans; LDL-C, low-density lipoprotein cholesterol; PEG-IFN $\alpha$, pegylated interferon alpha; RBV, ribavirin; HBV, hepatitis B virus; HDV, hepatitis D virus; BMI, body mass index; SVR, sustained virological response; TG, triglyceride; ApoC-III, apolipoprotein C-III.
}

LVP and PCSK9 in patients chronically infected with HCV genotype (G)3. PCSK9 concentrations were also measured in HCV-G1 to indirectly examine the role of LDLR in LVP clearance.

Methods: HCV RNA, LVP $(d<1.07 \mathrm{~g} / \mathrm{ml})$ and non-LVP $(d>1.07 \mathrm{~g} /$ $\mathrm{ml})$ fractions, were quantified in patients with HCV-G3 $(\mathrm{n}=39)$ by real time RT-PCR and LVP ratios (LVPr; LVP/(LVP + non-LVP)) were calculated. Insulin resistance (IR) was assessed using the homeostasis model assessment of IR (HOMA-IR). Plasma PCSK9 concentrations were measured by ELISA in HCV-G3 and HCVG1 $(\mathrm{n}=51)$.

Results: In HCV-G3 LVP load correlated inversely with HDL-C $(\mathrm{r}=-0.421 ; p=0.008)$, and apoE $(\mathrm{r}=-0.428 ; p=0.013)$. The LVPr varied more than 35 -fold (median 0.286 ; range 0.027 to 0.969 ); PCSK9 was the strongest negative predictor of $L \operatorname{VPr}\left(R^{2}=16.2 \%\right.$; $p=0.012$ ). HOMA-IR was not associated with LVP load or LVPr. PCSK9 concentrations were significantly lower in HCV-G3 compared to HCV-G1 $(p<0.001)$. PCSK9 did not correlate with LDL-C in HCV-G3 or G1.

Conclusions: The inverse correlation of LVP with apoE in HCV$\mathrm{G} 3$, compared to the reverse in HCV-G1 suggests HCV genotype-specific differences in apoE mediated viral entry. Lower PCSK9 and LDL concentrations imply upregulated LDLR activity in HCV-G3.

(c) 2014 European Association for the Study of the Liver. Published by Elsevier B.V. All rights reserved.

\section{Introduction}

Deaths from hepatitis $\mathrm{C}$ virus (HCV) have now superseded HIV as a cause of mortality in the United States and these deaths occur disproportionately in middle-aged persons [1]. HCV genotype 3 


\section{Research Article}

(HCV-G3) is the dominant genotype circulating in the UK and Southern Asia, and is most commonly found in European intravenous drug users [2]. Globally, it is estimated to account for 10$15 \%$ of the total number of HCV infections [3]. Chronic HCV-G3 patients have been found to have higher rates of late-stage liver disease and death [4], and HCV-G3 is now potentially the most difficult-to-treat genotype [5], most notably in these patients with decompensated cirrhosis.

HCV hijacks host lipid metabolism (reviewed in [6,7]) leading to steatosis and hypocholesterolaemia, which resolves with successful HCV treatment [8]. One striking feature of infectious $\mathrm{HCV}$ particles is their buoyant density, which is unusually low for an RNA virus [9], due to interaction with lipoproteins [10]. In patients' sera, HCV particles are found associated with verylow-density lipoprotein (VLDL) components (cholesterol, triglyceride, apolipoprotein (apo) B, apoE and apoCs), forming hybrid particles termed lipoviral particles (LVP). LVP can be immunoprecipitated with antibodies to apoB, apoE, and apoC1 [11,12]. ApoE is enriched on infectious particles and correlates with infectivity [13]; electron microscopy studies have visualised apoE on the HCV envelope $[14,15]$. Recent cryoelectron tomography studies have provided low-resolution 3D structural information on highly infectious virions and have shown that LVP incorporate apoB and apoA-I in addition to apoE [16].

Evidence has indicated that one function of HCV association with lipoproteins is the co-opting of lipoprotein receptors for attachment and entry into hepatocytes. The initial binding of LVP to cells occurs via interaction with low-density lipoprotein receptor (LDLR) and glycosaminoglycans present on heparan sulphate proteoglycans (HSPGs) [17] (reviewed in [18]). Both LDLR and HPSGs can interact with virion-associated apoE $[19,20]$. CD81 then mediates a post-attachment event in HCV entry [21].

Proprotein convertase subtilisin kexin type 9 (PCSK9) is a protease made by the liver. PCSK9 normally acts to enhance the degradation of the LDLR [22]. PCSK9 also modulates liver CD81 levels [23]. The circulating concentrations of human PCSK9 are directly correlated with LDL and total cholesterol concentrations in healthy human volunteers $[24,25]$. Reducing the concentration or activity of PCSK9 enables greater numbers of LDLR on the cell surface, thereby increasing the clearance of LDL particles from the circulation and reducing plasma LDL cholesterol. LDLR binds and internalises LDL via its unique proteins, apoB100 and apoE.

We have previously measured low-density apoB-associated LVP in patients with chronic HCV-G1 and found a positive association with serum triglycerides, insulin resistance (IR) [26], and serum apoE levels [27]. However, there is evidence that virushost interaction impacts on host lipid metabolism in ways, which may be HCV genotype-specific [28-30]. Therefore, we have, for the first time, examined LVP in the plasma of patients chronically infected with HCV-G3. We have measured PCSK9 concentrations in these patients and compared to patients chronically infected with HCV-G1 [26] to indirectly examine the role of LDLR in LVP clearance.

\section{Patients and methods}

Ethics

The Newcastle upon Tyne Hospitals NHS Foundation Trust acted as sponsor and the study was approved by Northumberland Research Ethics Committee (REC number-07/H0902/45)
Patients

Patients with chronic hepatitis $\mathrm{C}(\mathrm{CHC})$, attending the viral hepatitis clinic at the Freeman Hospital, Newcastle upon Tyne and St Mary's Hospital, Imperial College Healthcare Trust, London, were invited to participate and given a patient information leaflet explaining the study. Both treatment naïve and previous non-responders to a combination of pegylated interferon- $\alpha$ and ribavirin (PegIFN $\alpha / R B V$ ) antiviral therapy were eligible for inclusion. Patients were excluded if they were alcohol dependent, being treated with concurrent lipid lowering therapy, coinfected with HBV, HDV, or HIV or had poor venous access due to injecting drug use. Non-responders were also invited to participate in a separate lipid-modulating intervention study [31] which, in addition to the above, excluded participants with a body mass index $(\mathrm{BMI}) \geqslant 30$. BMI was calculated as weight divided by the square of the height $\left(\mathrm{kg} / \mathrm{m}^{2}\right)$. Thirty-nine patients with chronic HCV-G3 aged $>18$ years, who provided written informed consent, attended after a $12 \mathrm{~h}$ fast (fasting samples were essential in view of the post-prandial changes in buoyant density of HCV particles [32] and assessment of IR). Twenty-six of 39 patients were non-responders to PegIFN $\alpha / R B V$. Eleven patients achieved a sustained virological response (SVR) and two patients were treatment naïve.

Clinical and laboratory assessment

Each subject was assessed for past alcohol intake and medication history and the following data were collected: sex, age, weight, height, waist and hip circumference. A fasting serum sample was collected for lipid analysis. Total cholesterol, triglyceride (TG), HDL-cholesterol (HDL-C), and glucose were measured by standard automated enzymatic methods using an Olympus AU 640 analyser (Olympus, Watford, UK). LDL cholesterol (LDL-C) was calculated using the Friedewald equation [33]. Insulin was measured by immunoassay (ELISA - Dako UK Ltd, Ely, UK) and assessment of insulin resistance was performed by calculation of HOMA-IR using the formula: HOMA-IR $=($ fasting glucose $[\mathrm{mmol} / \mathrm{L}] \times$ insulin $[\mathrm{mU} / \mathrm{L}]) / 22.5)$. Apolipoproteins A-I, E and B were measured on each sample by automated rate nephelometric methods (BNII, Dade Behring Marburg GmbH, Marburg, Germany). ApoC-III was measured using a quantitative sandwich ELISA (AssayMax - AssayPro, St. Charles, USA). Fasting plasma PCSK9 concentrations were measured by ELISA [25], which was developed and validated in a group of 254 healthy individuals (the method is described in the Supplementary material). In addition, we measured PCSK9 in a well-characterised HCV-G1 infected cohort $(\mathrm{n}=51)[26]$.

Iodixanol gradient ultracentrifugation

The LVP-containing fraction was harvested using a method described in the Supplementary material and previously described [26].

Quantification of HCV RNA

The HCV RNA was quantitated using a method described in the Supplementary material.

PCSK9 ELISA

Plasma PCSK9 concentrations were determined using a validated ELISA, using a method described in the Supplementary material.

Statistical methods

All statistical methods used in this study are described in the Supplementary material.

\section{Results}

\section{Clinical characteristics of the patients with chronic HCV-G3}

The physical and metabolic characteristics of the 39 patients with CHC-G3 infection recruited in this study are summarised in Table 1 and fully detailed in Supplementary Table 1. Ethnicities 


\section{JOURNAL OF HEPATOLOGY}

Table 1. Characteristics of the patients with chronic hepatitis $\mathrm{C}$ virus genotype 3.

\begin{tabular}{|c|c|c|c|}
\hline Characteristic & HCV-G3 $(n=39)$ & High LVP ratio $(n=20)$ & $p$ value* \\
\hline Sex, n (M/F) & $30 / 9$ & $17 / 3$ & - \\
\hline Age $(y r)$, mean \pm SD & $48.2 \pm 10.5$ & $47.9 \pm 6.8$ & $0.86^{\S}$ \\
\hline Liver stiffness $\geq 13 \mathrm{kPa}, \mathrm{n}(\%)^{\dagger}$ & $12(30.8)$ & $8.8(9.1)$ & $0.92^{\pi}$ \\
\hline Waist $(\mathrm{cm})$, mean $\pm \mathrm{SD}$ & $89 \pm 10.1$ & $89.8 \pm 9.5$ & $0.63^{\S}$ \\
\hline Waist/hip ratio, median (IQR) & $0.96(0.08)$ & $0.97(0.06)$ & $0.61 \pi$ \\
\hline BMI $\left(\mathrm{kg} / \mathrm{m}^{2}\right)$, mean \pm SD & $25.3 \pm 3.0$ & $25.2 \pm 2.6$ & $0.92^{\S}$ \\
\hline Cholesterol $(\mathrm{mmol} / \mathrm{L})$, mean $\pm \mathrm{SD}$ & $3.74 \pm 0.90$ & $3.73 \pm 0.8$ & $0.92^{\S}$ \\
\hline LDL-C (mmol/L), mean \pm SD & $2.04 \pm 0.67$ & $2.2 \pm 0.7$ & $0.24 \S$ \\
\hline TG (mmol/L), median (IQR) & $0.85(0.50)$ & $0.86(0.63)$ & $0.88 \pi$ \\
\hline ApoB (g/L), median (IQR) & $0.60(0.30)$ & $0.7(0.20)$ & $0.07^{\pi}$ \\
\hline HDL-C (mmol/L), median (IQR) & $1.20(0.68)$ & $1.1(0.60)$ & $0.20 \pi$ \\
\hline ApoA-I (g/L), mean \pm SD & $1.41 \pm 0.35$ & $1.35 \pm 0.31$ & $0.25^{\S}$ \\
\hline TG/HDL-C ratio, median (IQR) & $0.60(0.66)$ & $0.72(1.19)$ & $0.39 \pi$ \\
\hline ApoC-III ( $\mu \mathrm{g} / \mathrm{ml})$, median (IQR) & $62.4(55.22)$ & $62.3(57.9)$ & $0.99 \pi$ \\
\hline ApoE (mg/L), median (IQR) & $30.0(19.5)$ & $28.5(14.0)$ & $0.39 \pi$ \\
\hline PCSK9 (ng/ml), median (IQR) & $60.7(39.0)$ & $50.4(45.1)$ & $0.04 \pi$ \\
\hline Glucose (mmol/L), median (IQR) & $5.20(1.30)$ & $5.2(1.30)$ & $0.92 \pi$ \\
\hline Insulin (mU/L), median (IQR) & $6.95(5.62)$ & $8.1(5.90)$ & $0.61 \pi$ \\
\hline HOMA-IR ${ }^{\ddagger}$, median (IQR) & $1.53(1.62)$ & $1.62(1.79)$ & $0.64 \pi$ \\
\hline HCV genotype, n (3a/3b/unknown) & 27/1/11 & $14 / 0 / 5$ & - \\
\hline Total viral load $\log _{10}(\mathrm{IU} / \mathrm{ml})$, median (IQR) & $6.06(0.78)$ & $5.87(1.03)$ & $0.4^{\pi}$ \\
\hline LVP load $\log _{10}(\mathrm{IU} / \mathrm{ml})$, mean \pm SD & $5.22 \pm 0.90$ & $5.53 \pm 0.94$ & $0.02^{\S}$ \\
\hline Non-LVP load $\log _{10}(\mathrm{IU} / \mathrm{ml})$, mean \pm SD & $5.62 \pm 0.86$ & $5.42 \pm 1.03$ & $0.13^{\S}$ \\
\hline LVP ratio, median (IQR) & $0.286(0.432)$ & $0.50(0.36)$ & $<0.001 \pi$ \\
\hline
\end{tabular}

ALT, alanine transaminase; BMI, body mass index; apoB, apolipoprotein B; apoA; apolipoprotein A-I; apoE, apolipoprotein E; apoC-III, apolipoprotein C-III; HDL-C, highdensity lipoprotein cholesterol; HOMA-IR, Homeostasis Model Assessments of Insulin Resistance; LDL-C, low-density lipoprotein cholesterol; LVP, lipoviral particle; PCSK9, proprotein convertase subtilisin/kexin type 9; TG, triglyceride.

Parametric data is shown with plus-minus values, which are the means \pm standard deviation. Non-parametric data is shown as the median value plus the interquartile range.

${ }^{*} p$ values are for the comparison between high/low LVP ratios (LVPr). $p<0.05$ were considered significant. High LVP ratio ( $\mathrm{n}=20$ ) is defined as greater than or equal to the median value of 0.286 .

${ }^{\dagger}$ Liver stiffness measured by transient elastography using a Fibroscan ${ }^{\mathrm{TM}}$ machine with a standard probe [52]. A score $\geqslant 13.0 \mathrm{kPa}$ represents cirrhosis [51].

${ }^{\ddagger}$ Assessment of insulin resistance was performed by calculation of Homeostasis Model Assessments of Insulin Resistance (HOMA-IR) from a fasting blood sample using the formula: (fasting glucose $(\mathrm{mmol} / \mathrm{L}) \times$ fasting insulin $(\mathrm{mU} / \mathrm{L})) / 22.5$.

$\S_{p}$ value calculated using the parametric $t$ test.

" $p$ value calculated using the non-parametric Kruskal-Wallis test.

were self-reported: Caucasian ( $\mathrm{n}=31)$, South Asian $(\mathrm{n}=3)$, Middle Eastern ( $\mathrm{n}=2)$, East Asian $(\mathrm{n}=1)$ and Mixed-other $(\mathrm{n}=2$; East/ South Asian). BMI was normal $\left(<25 \mathrm{~kg} / \mathrm{m}^{2}\right)$ in 17 patients, overweight $\left(25-30 \mathrm{~kg} / \mathrm{m}^{2}\right)$ in 21 patients, and obese $\left(>30 \mathrm{~kg} / \mathrm{m}^{2}\right)$ in 1 patient. According to the criteria of the International Diabetes Federation [34], 7 patients had metabolic syndrome. Of these, 2 patients were receiving treatment for type 2 diabetes mellitus. The virological characteristics of the patient cohort are also summarised in Table 1. The mean plasma HCV RNA viral load was $5.91 \log _{10}(\mathrm{IU} / \mathrm{ml})$ but ranged from 3.66 to $7.62 \log _{10}(\mathrm{IU} / \mathrm{ml})$. The mean HCV RNA LVP load was $5.22 \log _{10}(\mathrm{IU} / \mathrm{ml})$. The mean LVPr was 0.333 , but varied widely between patients ranging from 0.027 to 0.969 and the median LVPr was 0.286.

\section{Correlations between plasma viral load and metabolic factors}

The relationship between host metabolic factors with specific viral parameters (total viral load, LVP, and LVPr) was examined using either Pearson's or Spearman's ( $r$ ) rank correlation analysis. Using Spearman's rank correlation analysis, a number of metabolic factors correlated with total viral load (Fig. 1). There was a significant negative correlation between total viral load and TC (Fig. $1 \mathrm{~A} ; \mathrm{r}=-0.450 ; p=0.004$ ), LDL-C (Fig. 1B; $\mathrm{r}=-0.444$; $p=0.005$ ), apoB (Fig. $1 \mathrm{C} ; \mathrm{r}=-0.352 ; p=0.028$ ) and apoA-I (Fig. 1D; $r=-0.409 ; p=0.010$ ). In multivariable stepwise regression analysis, many of the significant correlates identified interacted, but after 3 rounds of backward elimination of the weakest predictors, LDL-C was the significant independent determinant of total viral load $\left(\mathrm{R}^{2}=10.7 \% ; p=0.042\right)$. Thus, in HCV-G3, the higher viral load, the lower the concentration of LDL-C.

\section{Correlations between LVP and metabolic factors}

The association of LVP load with metabolic factors was evaluated with univariate correlation analysis (Fig. 2). LVP load correlated negatively with HDL-C (Fig. 2A; $r=-0.421 ; p=0.008$ ), apoA-I (Fig. 2C; $r=-0.394 ; p=0.013$ ), and apoE (Fig. 2E; $r=-0.428$; $p=0.013)$. The comparison of these factors with LVP was further evaluated by separating LVP load into high LVP (defined as above the median value of $5.375 \log _{10}$ HCV RNA (IU/ml)) and low LVP (defined as below the median value of $5.375 \log _{10}$ HCV RNA $(\mathrm{IU} / \mathrm{ml})$ ). High LVP load was associated with significantly lower 


\section{Research Article}

HDL-C (Fig. 2B; $1.14 \pm 0.40 \mathrm{mmol} / \mathrm{L}$ vs. $1.40 \pm 0.46 \mathrm{mmol} / \mathrm{L}$, $p=0.047$ ), apoA-I (Fig. 2D; $1.31 \pm 0.32 \mathrm{~g} / \mathrm{L}$ vs. $1.53 \pm 0.34 \mathrm{~g} / \mathrm{L}$, $p=0.044$ ), and apoE (Fig. 2F; $29.8 \pm 13.2 \mathrm{mg} / \mathrm{L}$ vs. $41.13 \pm$ $19 \mathrm{mg} / \mathrm{L}, p=0.020$ ). Multivariable stepwise regression analysis of the relationship between LVP load and these correlates (with backward elimination of the weakest predictive factors) showed that after two rounds HDL-C was the most significant
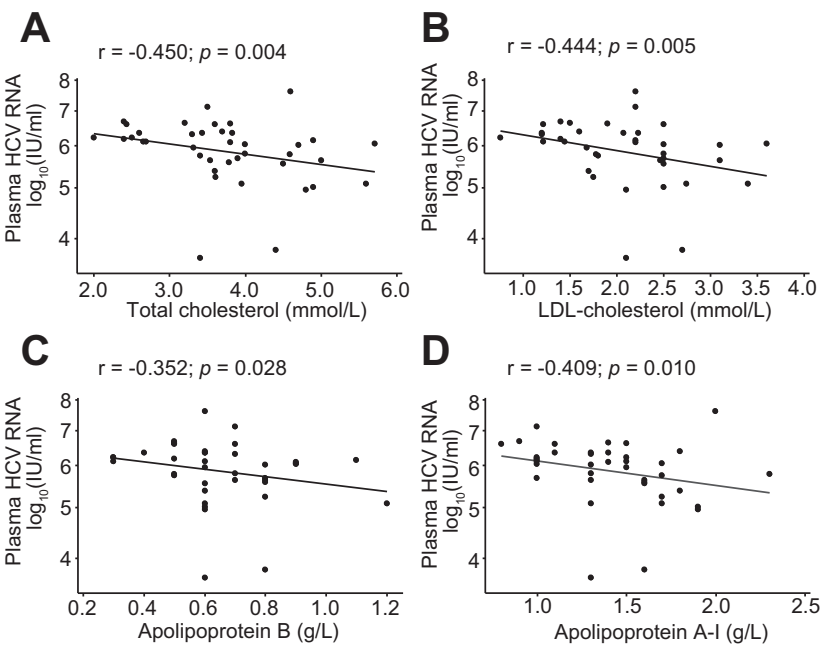

Fig. 1. Relationship between total viral loads and lipoproteins/apolipoproteins in HCV-G3. Total viral loads correlated negatively with (A) total cholestero $(\mathrm{r}=-0.450 ; p=0.004)$, (B) LDL-C $(\mathrm{r}=-0.444 ; p=0.005)$, (C) apolipoprotein $\mathrm{B}$ $(\mathrm{r}=-0.352 ; p=0.028)$, and (D) apolipoprotein A-I $(\mathrm{r}=-0.409 ; p=0.010)$. determinant of LVP load $\left(\mathrm{R}^{2}=17.8 \% ; p=0.008\right)$. Thus, in HCVG3 the higher the HDL-C the lower the LVP load.

Correlation between LVP ratio and metabolic factors

In patients with HCV-G3, neither LVP load (Supplementary Fig. $1 \mathrm{~A}, \mathrm{r}=-0.029 ; p=0.863$ ) or LVP ratio (Supplementary Fig. $1 \mathrm{~B}, \mathrm{r}=0.010 ; p=0.952$ ) showed evidence of an association with HOMA-IR. We found a negative correlation between LVPr with PCSK9 in HCV-G3 (Fig. 3A; $r=-0.478, p=0.002$ ) and the correlation remained significant after excluding the two outliers $(\mathrm{r}=-0.403 ; p=0.015)$, whereas in HCV-G1, LVPr [26] trended towards a positive correlation with PCSK9 (Fig. 3C, $r=0.267$; $p=0.058$ ). In HCV-G3, regression analysis (this model excludes unusual observations (outliers) with very high or very low PCSK9 concentrations) showed that PCSK9 concentration was a significant independent predictor of $\operatorname{LVPr}\left(\mathrm{R}^{2}=16.2 \%\right.$; $\left.p=0.012\right)$.

Stratification of LVP ratio into high and low LVP ratio

The comparison of clinical and metabolic variables in patients with chronic HCV-G3 with a low LVPr (defined as below the median value of $0.286 ; n=19$ ) and those with a high LVPr (defined as above the median value of $0.286 ; n=20$ ) is shown in Table 1 . The only significant difference between patients with a high or low LVPr was found in PCSK9 concentrations $(50.4 \mathrm{ng} / \mathrm{ml} v s$. $76.3 \mathrm{ng} / \mathrm{ml} ; p=0.044$ ) which is shown in Fig. 3B. Therefore, in patients with chronic HCV-G3, we have shown that higher LVP ratio is associated with lower PCSK9 concentration. We compared the PCSK9 concentrations between high and low LVP ratios in the HCV-G1 cohort and found that higher LVP ratios are associated
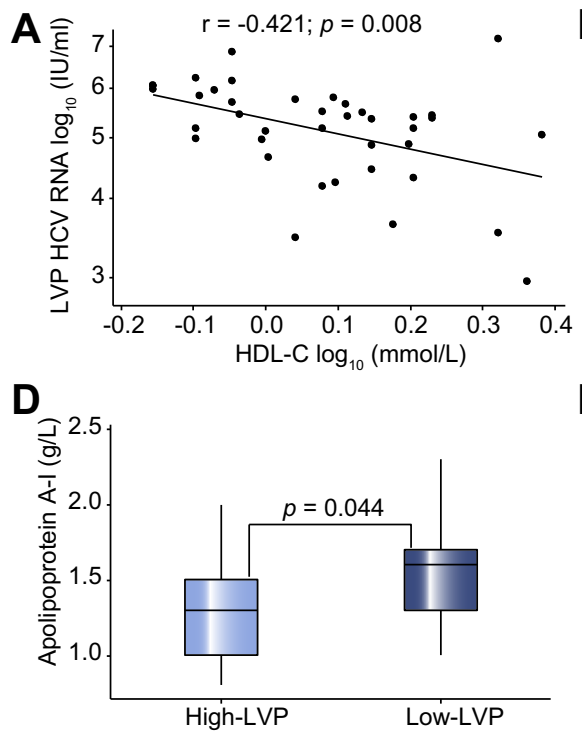

HCV RNA in LVP-containing fraction $\log _{10}(\mathrm{IU} / \mathrm{ml})$

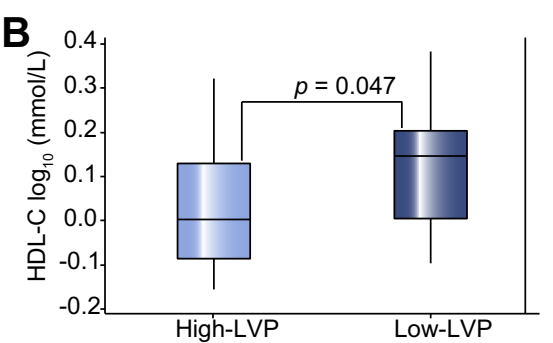

HCV RNA in LVP-containing fraction $\log _{10}(\mathrm{IU} / \mathrm{ml})$

E

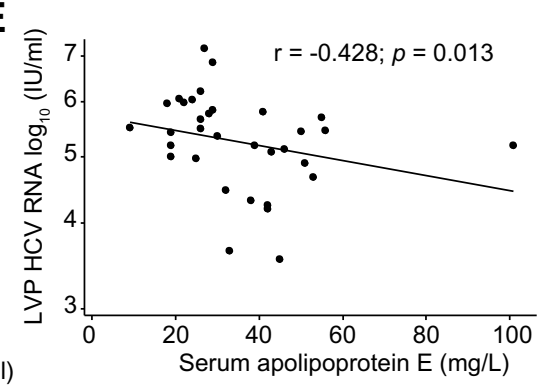

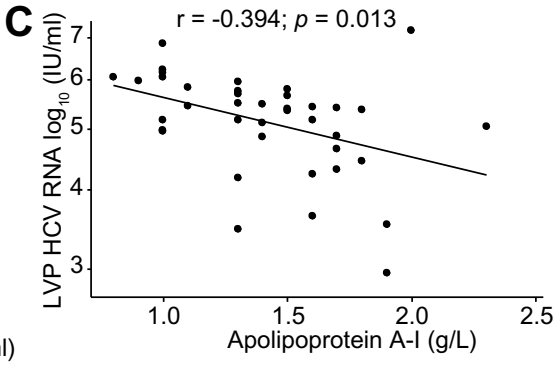

$\mathbf{F}$

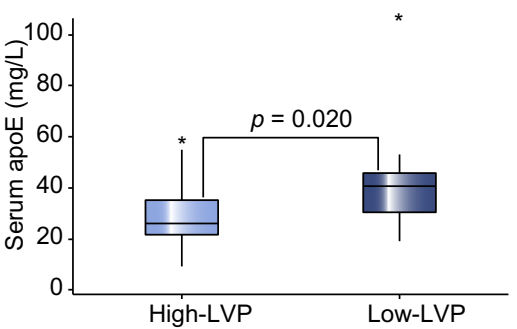

HCV RNA in LVP-containing fraction $\log _{10}(\mathrm{IU} / \mathrm{ml})$

Fig. 2. Relationship between lipoviral particle (LVP) load and high-density lipoprotein cholesterol (HDL-C), apoA-I, and apoE. (A) Negative correlation between HDL-C and LVP load ( $\mathrm{r}=-0.421 ; p=0.008)$. (B) Boxplot showing high LVP load is associated with significantly lower HDL-C (1.14 $\pm 0.40 \mathrm{mmol} / \mathrm{L} v \mathrm{~s}$. $1.40 \pm 0.46 \mathrm{mmol} / \mathrm{L}, p=0.047)$. (C) Negative correlation between apoA-I and LVP load ( $\mathrm{r}=-0.394 ; p=0.013)$. (D) Boxplot showing high LVP is associated with significantly lower apoA-I (1.31 $\pm 0.32 \mathrm{~g} / \mathrm{L} v$. $1.53 \pm 0.34 \mathrm{~g} / \mathrm{L}, p=0.044)$. (E) Negative correlation between apoE and LVP load $(\mathrm{r}=-0.428 ; p=0.013)$ and $(\mathrm{F})$ boxplot showing high LVP load is associated with significantly lower apoE $(29.8 \pm 13.2 \mathrm{mg} / \mathrm{L}$ vs. $41.13 \pm 19 \mathrm{mg} / \mathrm{L}, p=0.020)$. The box height represents the interquartile range (Q1-Q3), the line within the box is the median value, the lower whisker represents Q1 - 1.5 (Q3-Q1), and the upper whisker represents Q3 + 1.5 (Q3-Q1). 
A

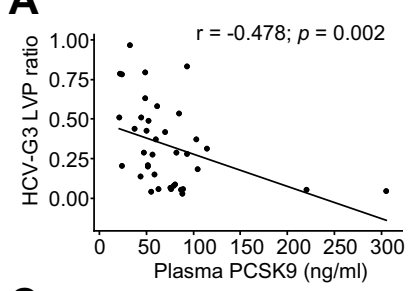

C

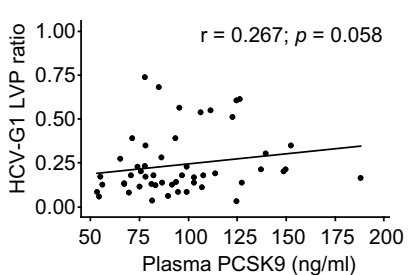

B

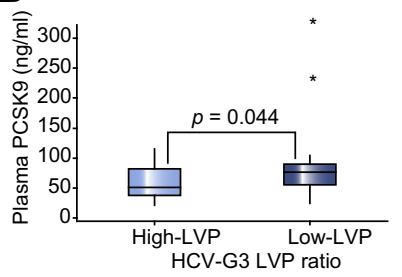

D

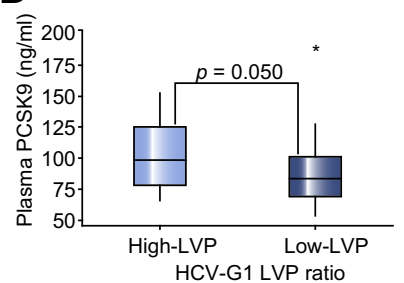

Fig. 3. Relationship between plasma proprotein convertase subtilisin/kexin type 9 (PCSK9) concentration, as measured by ELISA, and LVP ratio in HCV-G3 and HCV-G1 infection. (A) Negative correlation in HCV-G3 patients between PCSK9 concentration and LVP ratio $(r=-0.478 ; p=0.002)$. (B) Boxplots showing the relationship between plasma PCSK9 concentration with high and low LVP ratio (50.4 ng/ml vs. $76.3 \mathrm{ng} / \mathrm{ml} ; p=0.044)$ in HCV-G3 patients. (C) Trend towards a significant positive correlation patients between plasma PCSK9 concentration and LVP ratio $(r=0.276 ; p=0.058)$ in HCV-G1 and (D) boxplots showing the relationship between plasma PCSK9 and high and low LVP ratio $(98 \mathrm{ng} / \mathrm{ml} v s$. $83.2 \mathrm{ng} / \mathrm{ml} ; p=0.05$ ) in HCV-G1 patients.

with higher PCSK9 concentrations (98.0 ng/ml vs. $83.2 \mathrm{ng} / \mathrm{ml}$; $p=0.05$ ) (Fig. 3D).

\section{PCSK9 concentrations are lower in HCV-G3 compared to HCV-G1}

PCSK9 was measured in both the HCV-G3 and HCV-G1 infected patients $(n=51 ;[26])$ and compared to the PCSK9 concentrations in HCV negative individuals $(\mathrm{n}=254$; [25]), Supplementary Fig 2A. PCSK9 concentrations were significantly lower in HCV-G3 patients compared to HCV-G1 (Fig. 2A; $73.8 \pm 52.2 \mathrm{ng} / \mathrm{ml}$ vs. $96.1 \pm 28.7 \mathrm{ng} / \mathrm{ml} ; p<0.001)$. PCSK9 concentrations were also significantly lower in HCV-G3 patients compared to HCV negative individuals (Fig. 2A; $73.8 \pm 52.2 \mathrm{ng} / \mathrm{ml}$ vs. $89.4 \pm 31.9 \mathrm{ng} / \mathrm{ml}$; $p=<0.001$ ). The concentration of PCSK9 in HCV-G1 patients was found to be significantly higher than in HCV negative subjects (Fig. 2A; $96.1 \pm 28.7 \mathrm{ng} / \mathrm{ml}$ vs. $89.4 \pm 31.9 \mathrm{ng} / \mathrm{ml} ; \quad p=0.049$ ). Although the PCSK9 concentrations were relatively low in HCVG3, given the low concentrations of LDL-C, the plasma PCSK9 and PCSK9/LDL-C ratio were somewhat higher than expected. In HCV-G3, the PCSK9/LDL-C ratio was $43.9 \pm 46.3$ and HCV-G1 $39.9 \pm 19.9$, compared to $33.2 \pm 12.9$ in 254 HCV negative individuals. There were no statistically significant differences between the groups as shown in Supplementary Fig. 2B. The differences remained insignificant after exclusion of the two HCV-G3 outliers with very high PCSK9 concentrations and PCSK9/LDL-C ratios (36.4 \pm 18.7 vs. $39.9 \pm 19.9 ; p=0.264$ ).

Using univariate correlation analysis, we found that PCSK9 concentrations did not correlate with either total cholesterol or LDL-C in either HCV-G1 or HCV-G3 infected patients, which is in contrast to the $\mathrm{HCV}$ negative subjects, where a correlation was found between the PCSK9 concentrations with either total or LDL cholesterols (Fig. 4). The relationship between PCSK9 concentrations and biomarkers of liver inflammation, e.g., ALT, AST and GGT were also evaluated (Supplementary Fig. 3). It is

\section{JOURNAL OF HEPATOLOGY}

noteworthy that the two PCSK9 outliers with very high PCSK9 concentrations were found to have low LDL-C and much higher liver stiffness measurements $(>13 \mathrm{kPa})$, as determined by transient elastography.

\section{Discussion}

In chronic HCV infection, viral load is not a useful prognostic indicator of the severity of liver disease [35] and is influenced by a large number of demographic, viral, and human genetic factors [36]. In this study of HCV-G3 patients, we found that LDL-C was a significant determinant of total viral load; i.e., higher viral load, lower LDL-C. It has previously been shown that liver steatosis is independently associated with HCV-G3 [37] and that steatosis correlates with lower LDL-C and hypobetalipoproteinaemia [38]. In addition, steatosis grade correlates with higher viral load [39], and steatosis is a predictor of virological relapse to antiviral therapy in HCV-G3 [40]. Our finding emphasises the link between HCV-G3 replication, steatosis, viral load, and LDL-C. This suggests that LDL$\mathrm{C}$ should be included in the parameters examined as predictors of virological relapse in the era of direct acting antivirals [41].

The poor correlation between viral load and disease severity in chronic HCV could be partially explained by the increasing evidence that not all of the HCV RNA is equally infectious. Infectious $\mathrm{HCV}$ particles have a low buoyant density, due to interaction with lipoproteins to form hybrid lipoviral particles [10] that can facilitate virus entry into hepatocytes (reviewed in [18]). This is the first study to quantitate LVP in the plasma of patients with HCV-G3, and a striking finding is that LVP load is negatively correlated with apoE; i.e., higher LVP load, lower serum apoE. This might seem surprising, as LVP can be immunoprecipitated with anti-apoE [11,42] and apoE is enriched on the surface of HCVcc [15]. There is also evidence that apoE mediates attachment of clinical HCV to hepatocytes by binding to cell surface heparan sulphate proteoglycan receptors [20]. Our finding in HCV-G3 is the opposite of HCV-G1, where we showed that LVP load positively correlates with apoE [27]. One interpretation of our opposing findings in HCV-G3 vs. HCV-G1 is that apoE is depleted by LDLR-mediated uptake of LVP, thereby mediating viral entry into hepatocytes in HCV-G3 in vivo.

In this study, we found that the most significant determinant of fasting LVP load in G3 is HDL-C; i.e., higher HDL-C, lower LVP load. We have previously shown that HCV particles in the serum exhibit post-prandial shifts in buoyant density [32], moving on to very-low-density apoB-associated triglyceride-rich lipoproteins (TRLs) after a fatty meal. The reciprocal relationship between HDL-C and LVP found in HCV-G3 infection suggests slower clearance of HDL-bound HCV RNA containing particles retained in the higher density fraction.

LVP load in HCV-G3 did not correlate with insulin resistance as measured by HOMA-IR, unlike HCV-G1 [26]. Insulin plays a central role in coordinating lipoprotein metabolism and promotes the uptake of TRL remnant particles $[43,44]$, however, insulin resistance is associated with overproduction of TRLs. Our finding in HCV-G3 vs. HCV-G1 again implies genotype-specific differences in the regulation of the pathways of TRL production and TRL remnant clearance, the latter being more important in HCV-G3 compared with HCV-G1.

This is also the first report of PCSK9 concentrations in HCV patients. PCSK9 regulates recycling of the LDLR and plasma PCSK9 concentrations normally correlate inversely with LDLR 
Research Article

A

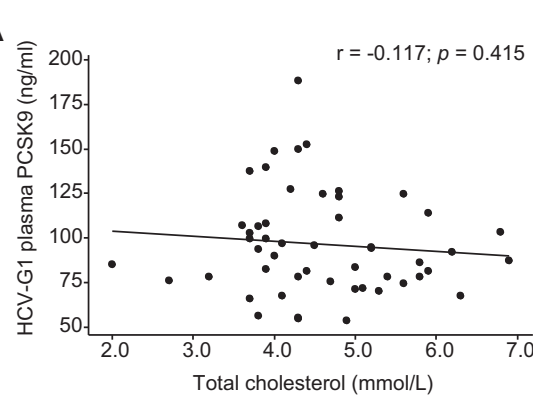

D

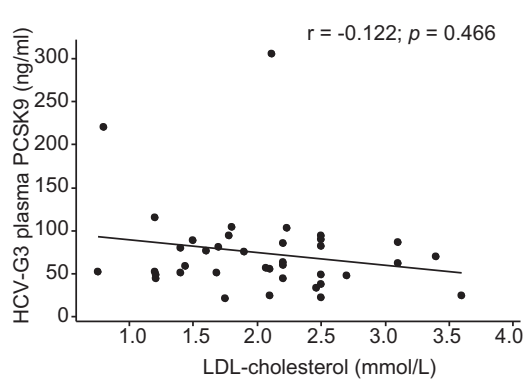

B

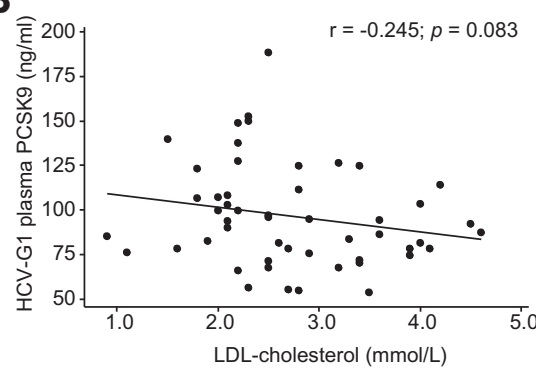

E

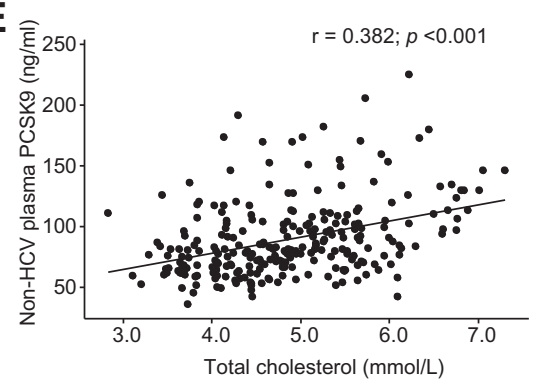

C
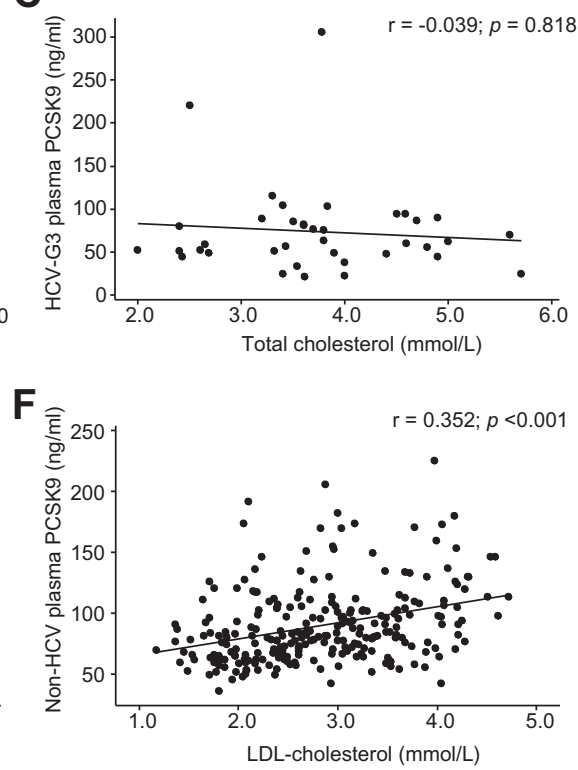

Fig. 4. Relationship between plasma proprotein convertase subtilisin/kexin type 9 (PCSK9) levels and serum total and LDL-cholesterol in HCV-G1 ( $\mathrm{n}=51$; [26]), HCVG3 ( $\mathbf{n}=39$ ) and non-HCV infected subjects ( $\mathbf{n}=\mathbf{2 5 4}$; [25]). (A) PCSK9 does not correlate with total cholesterol in HCV-G1 ( $\mathrm{r}=-0.117$; $p=0.415)$, (B) PCSK9 does not correlate with LDL-C in HCV-G1 ( $r=-0.245 ; p=0.083$ ), (C) PCSK9 does not correlate with serum cholesterol in HCV-G3 ( $\mathrm{r}=-0.039 ; p=0.818$ ), (D) PCSK9 does not correlate with serum LDL-C in HCV-G3 $(r=-0.122 ; p=0.466)$, (E) PCSK9 correlates with total cholesterol in 254 non-HCV infected study participants ( $r=0.382 ; p=<0.001)$ and (F) PCSK9 correlates with LDL cholesterol in non-HCV infected individuals $(r=0.352 ; p=<0.001)$.

expression, hence positively with plasma LDL-C concentrations in healthy individuals [45] (reviewed in [22,46]). We found that plasma PCSK9 did not correlate with total cholesterol or LDL-C in HCV-G3 and HCV-G1 patients, indicating disruption of lipid homeostatic mechanisms by HCV. PCSK9 concentrations were significantly lower in HCV-G3 vs. HCV-G1. In apoB kinetic studies, fasting PCSK9 concentrations correlate inversely with apoB fractional catabolic rate; i.e., lower PCSK9 is associated with high LDL clearance via LDLR [47]. Thus, a lower PCSK9 concentration in HCV-G3 supports the concept that chronic HCV-G3 is characterised by increased clearance of both LDL-C and LVP mediated by LDLR. It also implies that increased clearance of apobetalipoproteins contributes to the hypobetalipoproteinaemia found in HCV-G3. Our findings suggest that HCV-G3 acts in an analogous manner to statins in that higher viral replication correlates with lower LDL-C and apparent upregulation of LDLR. This would normally be counteracted by upregulation of PCSK9 mediated homeostatic mechanism(s), and increased PCSK9 concentrations, as seen in statin treatment. Studies of the relationship between apoB kinetics and markers of sterol synthesis and absorption are needed in patients with chronic HCV, to elucidate the mechanism underlying these findings and to confirm that the low apoB concentrations, particularly in chronic HCV-G3, are not primarily due to decreased apoB production, as has been assumed as a consequence of MTP inhibition [48]. However, it must be emphasised that the undertaking of such demanding studies is fraught with difficulty in this patients' group. This study also highlights that the use of PCSK9 inhibitors may be hazardous in this patients' group as they could further increase LDLR mediated LVP uptake and enhance the severity of infection in HCV-G3.

In summary, the difference in LVP correlations in HCV-G3 compared to HCV-G1 $[26,27]$ suggests important differences in HCV entry for these 2 genotypes. ApoE-mediated entry via LDLR may be more dominant in HCV-G3 whereas apoE-mediated clearance via the SR-B1 pathway could be more important in vivo for HCV-G1 infection. This would mean that statins may be more beneficial as adjunct therapy in HCV-G1 rather than HCV-G3, as has been reported in a recent study [49]. The genotype-specific differences in lipoprotein interactions found in vivo in this study are likely to be of relevance, not only for blocking viral entry, but also for designing approaches to targeting host lipid pathways as adjunctive therapy [50].

\section{Financial support}

SHB, DAS, DJF, GLT, RDGN, and MFB were supported by the Medical Research Council (G0502028) and the Newcastle upon Tyne Healthcare Charity. HCT, MMEC, and SDT-R were supported by the NIHR Biomedical Facility at Imperial College London. NGS was supported by a CIHR grant and a Canada Chair. SHB is supported by an Anniversary Research Fellowship from Northumbria University.

\section{Conflict of interest}

The authors who have taken part in this study declared that they do not have anything to disclose regarding funding or conflict of interest with respect to this manuscript.

\section{Authors' contributions}

MFB, RDGN, HCT, SDT-R, and GLT conceived the study. SHB, DAS, DJF, MMEC, SDT-R, HCT, GLT, RDGN, and MFB were study investigators. DAS, MMEC, SDT-R, and MFB participated in the 


\section{JOURNAL OF HEPATOLOGY}

recruitment of patients and reporting of data for the enrolled patients. SHB, DAS, and DJF designed and performed experiments. SHB performed the statistical analysis. GD, NS, and JD contributed important reagents and collaborated with the study investigators. SHB, DAS, DJF, CVL, GLT, RDGN, and MFB contributed to the analysis and interpretation of data. SHB, RDGN, and MFB drafted and wrote the manuscript. All authors reviewed and revised the manuscript for intellectual content, and approved the final version for submission.

\section{Acknowledgements}

SDT-R, MMEC, and HCT are grateful to the NIHR Biomedical Facility at Imperial College London for infrastructure support and to Claire Parsonage for assistance with biobanking facilities at Imperial College. We thank Pete Philipson for his statistical advice and the patients that participated in this study.

\section{Supplementary data}

Supplementary data associated with this article can be found, in the online version, at http://dx.doi.org/10.1016/j.jhep.2014.11. 016.

\section{References}

[1] Ly KN, Xing J, Klevens RM, Jiles RB, Ward JW, Holmberg SD. The increasing burden of mortality from viral hepatitis in the United States between 1999 and 2007. Ann Intern Med 2012;156:271-278.

[2] Goossens N, Negro F. Is genotype 3 of the hepatitis C virus the new villain? Hepatology 2014;59:2403-2412.

[3] Negro F, Alberti A. The global health burden of hepatitis $C$ virus infection. Liver Int 2011;31:1-3.

[4] McCombs J, Matsuda T, Tonnu-Mihara I, Saab S, Hines P, L'Italien G, et al. The risk of long-term morbidity and mortality in patients with chronic hepatitis C: results from an analysis of data from a Department of Veterans Affairs Clinical Registry. JAMA Intern Med 2014;174:204-212.

[5] Tapper EB, Afdhal NH. Is 3 the new 1: perspectives on virology, natural history and treatment for hepatitis C genotype 3. J Viral Hepat 2013;20:669-677.

[6] Bassendine MF, Sheridan DA, Bridge SH, Felmlee DJ, Neely RD. Lipids and HCV. Semin Immunopathol 2013;35:87-100.

[7] Felmlee DJ, Hafirassou ML, Lefevre M, Baumert TF, Schuster C. Hepatitis C virus, cholesterol and lipoproteins - impact for the viral life cycle and pathogenesis of liver disease. Viruses 2013;5:1292-1324.

[8] Corey KE, Kane E, Munroe C, Barlow LL, Zheng H, Chung RT. Hepatitis C virus infection and its clearance alter circulating lipids: implications for long-term follow-up. Hepatology 2009;50:1030-1037.

[9] Podevin P, Carpentier A, Pene V, Aoudjehane L, Carriere M, Zaidi S, et al. Production of infectious hepatitis $C$ virus in primary cultures of human adult hepatocytes. Gastroenterology 2010;139:1355-1364.

[10] Bartenschlager R, Penin F, Lohmann V, Andre P. Assembly of infectious hepatitis C virus particles. Trends Microbiol 2011;19:95-103

[11] Nielsen SU, Bassendine MF, Burt AD, Martin C, Pumeechockchai W, Toms GL. Association between hepatitis C virus and very-low-density lipoprotein (VLDL)/LDL analyzed in iodixanol density gradients. J Virol 2006;80: 2418-2428.

[12] Meunier JC, Russell RS, Engle RE, Faulk KN, Purcell RH, Emerson SU. Apolipoprotein c1 association with hepatitis C virus. J Virol 2008;82: 9647-9656.

[13] Chang KS, Jiang J, Cai Z, Luo G. Human apolipoprotein e is required for infectivity and production of hepatitis $\mathrm{C}$ virus in cell culture. J Virol 2007:81:13783-13793.

[14] Gastaminza P, Dryden KA, Boyd B, Wood MR, Law M, Yeager M, et al. Ultrastructural and biophysical characterization of hepatitis $C$ virus particles produced in cell culture. J Virol 2010;84:10999-11009.
[15] Merz A, Long G, Hiet MS, Brugger B, Chlanda P, Andre P, et al, Biochemical and morphological properties of hepatitis $C$ virus particles and determination of their lipidome. J Biol Chem 2011;286:3018-3032.

[16] Catanese MT, Uryu K, Kopp M, Edwards TJ, Andrus L, Rice WJ, et al Ultrastructural analysis of hepatitis C virus particles. Proc Natl Acad Sci U S A 2013;110:9505-9510.

[17] Shi Q Jiang J, Luo G. Syndecan-1 serves as the major receptor for attachment of hepatitis C virus to the surfaces of hepatocytes. J Virol 2013;87: 6866-6875.

[18] Lindenbach BD, Rice CM. The ins and outs of hepatitis C virus entry and assembly. Nat Rev Microbiol 2013;11:688-700.

[19] Owen DM, Huang H, Ye J, Gale Jr M. Apolipoprotein E on hepatitis C virion facilitates infection through interaction with low-density lipoprotein receptor. Virology 2009;394:99-108.

[20] Jiang J, Wu X, Tang H, Luo G. Apolipoprotein e mediates attachment of clinical hepatitis $C$ virus to hepatocytes by binding to cell surface heparan sulfate proteoglycan receptors. PLoS ONE 2013;8:e67982.

[21] Zhang J, Randall G, Higginbottom A, Monk P, Rice CM, McKeating JA. CD81 is required for hepatitis $C$ virus glycoprotein-mediated viral infection. J Virol 2004;78:1448-1455.

[22] Seidah NG, Awan Z, Chretien M, Mbikay M. PCSK9: a key modulator of cardiovascular health. Circ Res 2014;114:1022-1036.

[23] Labonte P, Begley S, Guevin C, Asselin MC, Nassoury N, Mayer G, et al. PCSKS impedes hepatitis $\mathrm{C}$ virus infection in vitro and modulates liver CD81 expression. Hepatology 2009;50:17-24.

[24] Alborn WE, Cao G, Careskey HE, Oian YW, Subramaniam DR, Davies J, et al. Serum proprotein convertase subtilisin kexin type 9 is correlated directly with serum LDL cholesterol. Clin Chem 2007;53:1814-1819.

[25] Dubuc G, Tremblay M, Pare G, Jacques H, Hamelin J, Benjannet S, et al. A new method for measurement of total plasma PCSK9: clinical applications. J Lipid Res 2010;51:140-149.

[26] Bridge SH, Sheridan DA, Felmlee DJ, Nielsen SU, Thomas HC, Taylor-Robinson $\mathrm{SD}$, et al. Insulin resistance and low-density apolipoprotein B-associated lipoviral particles in hepatitis C virus genotype 1 infection. Gut 2011;60: 680-687.

[27] Sheridan DA, Bridge SH, Felmlee DJ, Crossey MM, Thomas HC, TaylorRobinson SD, et al. Apolipoprotein-E and hepatitis C lipoviral particles in genotype 1 infection: evidence for an association with interferon sensitivity. J Hepatol 2012;57:32-38.

[28] Roingeard P. Hepatitis C virus diversity and hepatic steatosis. J Viral Hepat $2013 ; 20: 77-84$

[29] Cai T, Dufour JF, Muellhaupt B, Gerlach T, Heim M, Moradpour D, et al. Viral genotype-specific role of PNPLA3, PPARG, MTTP, and IL28B in hepatitis C virus-associated steatosis. J Hepatol 2011;55:529-535.

[30] Rojas A, Del Campo JA, Maraver M, Aparcero R, Garcia-Valdecasas M, Diago $M$, et al. Hepatitis $C$ virus infection alters lipid metabolism depending on IL28B polymorphism and viral genotype and modulates gene expression in vivo and in vitro. J Viral Hepat 2014;21:19-24.

[31] Sheridan DA, Bridge SH, Crossey MM, Felmlee DJ, Fenwick FI, Thomas HC et al. Omega-3 fatty acids and/or fluvastatin in hepatitis C prior nonresponders to combination antiviral therapy - a pilot randomised clinical trial. Liver Int 2014:34:737-747.

[32] Felmlee DJ, Sheridan DA, Bridge SH, Nielsen SU, Milne RW, Packard CJ, et al. Intravascular transfer contributes to postprandial increase in numbers of very-low-density hepatitis C virus particles. Gastroenterology 2010;139: $1774-1783$.

[33] Friedewald WT, Levy RI, Fredrickson DS, Estimation of the concentration of low-density lipoprotein cholesterol in plasma, without use of the preparative ultracentrifuge. Clin Chem 1972;18:499-502.

[34] Alberti KG, Zimmet P, Shaw JGroup IDFETFC. The metabolic syndrome new worldwide definition. Lancet 2005;366:1059-1062.

[35] Hollingsworth RC, Sillekens P, van Deursen P, Neal KR, Irving WL. Serum HCV RNA levels assessed by quantitative NASBA: stability of viral load over time, and lack of correlation with liver disease. The Trent HCV Study Group. J Hepatol 1996;25:301-306.

[36] Uccellini L, Tseng FC, Monaco A, Shebl FM, Pfeiffer R, Dotrang M, et al. HCV RNA levels in a multiethnic cohort of injection drug users: human genetic viral and demographic associations. Hepatology 2012;56:86-94.

[37] Leandro G, Mangia A, Hui J, Fabris P, Rubbia-Brandt L, Colloredo G, et al. Relationship between steatosis, inflammation, and fibrosis in chronic hepatitis C: a meta-analysis of individual patient data. Gastroenterology 2006:130:1636-1642

[38] Serfaty L, Andreani T, Giral P, Carbonell N, Chazouilleres O, Poupon R. Hepatitis C virus induced hypobetalipoproteinemia: a possible mechanism for steatosis in chronic hepatitis C. J Hepatol 2001;34:428-434. 
Research Article

[39] Adinolfi LE, Gambardella M, Andreana A, Tripodi MF, Utili R, Ruggiero G. Steatosis accelerates the progression of liver damage of chronic hepatitis $C$ patients and correlates with specific HCV genotype and visceral obesity. Hepatology 2001;33:1358-1364.

[40] Shah SR, Patel K, Marcellin P, Foster GR, Manns M, Kottilil S, et al. Steatosis is an independent predictor of relapse following rapid virologic response in patients with HCV genotype 3. Clin Gastroenterol Hepatol 2011;9: 688-693.

[41] Sheridan DA, Neely RD, Bassendine MF. Hepatitis C virus and lipids in the era of direct acting antivirals (DAAs). Clin Res Hepatol Gastroenterol 2013;37: $10-16$.

[42] Andre P, Komurian-Pradel F, Deforges S, Perret M, Berland JL, Sodoyer M, et al. Characterization of low- and very-low-density hepatitis C virus RNAcontaining particles. J Virol 2002;76:6919-6928.

[43] Haas ME, Attie AD, Biddinger SB. The regulation of ApoB metabolism by insulin. Trends Endocrinol Metab 2013;24:391-397.

[44] Choi SH, Ginsberg HN. Increased very low density lipoprotein (VLDL) secretion, hepatic steatosis, and insulin resistance. Trends Endocrinol Metab 2011;22:353-363.

[45] Lakoski SG, Lagace TA, Cohen JC, Horton JD, Hobbs HH. Genetic and metabolic determinants of plasma PCSK9 levels. J Clin Endocrinol Metab 2009;94:2537-2543.
[46] Horton JD, Cohen JC, Hobbs HH. PCSK9: a convertase that coordinates LDL catabolism. J Lipid Res 2009;50:S172-S177.

47] Chan DC, Lambert G, Barrett PH, Rye KA, Ooi EM, Watts GF. Plasma proprotein convertase subtilisin/kexin type 9: a marker of LDL apolipoprotein B-100 catabolism? Clin Chem 2009;55:2049-2052.

[48] Perlemuter G, Sabile A, Letteron P, Vona G, Topilco A, Chretien Y, et al. Hepatitis C virus core protein inhibits microsomal triglyceride transfer protein activity and very low density lipoprotein secretion: a model of viralrelated steatosis. FASEB J 2002;16:185-194.

[49] Selic Kurincic T, Lesnicar G, Poljak M, Meglic Volkar J, Rajter M, Prah J, et al. Impact of added fluvastatin to standard-of-care treatment on sustained virological response in naive chronic hepatitis C Patients infected with genotypes 1 and 3. Intervirology 2014;57:23-30.

[50] Bassendine MF, Sheridan DA, Felmlee DJ, Bridge SH, Toms GL, Neely RD. HCV and the hepatic lipid pathway as a potential treatment target. J Hepatol 2011;55:1428-1440.

[51] Friedrich-Rust M, Ong MF, Martens S, Sarrazin C, Bojunga J, Zeuzem S, et al. Performance of transient elastography for the staging of liver fibrosis: a meta-analysis. Gastroenterology 2008;134:960-974.

[52] Ziol M, Handra-Luca A, Kettaneh A, Christidis C, Mal F, Kazemi F, et al. Noninvasive assessment of liver fibrosis by measurement of stiffness in patients with chronic hepatitis C. Hepatology 2005;41:48-54. 